\title{
Seeing Through an Empty Lot
}

\author{
Steven N. Handel
}

"N othing's there," they say. Time for some action. The scene is a plot of land with no buildings, no tall trees, few signs of wildlife, and maybe rubble or trash or pooling water on the ground. If the evaluators are land developers, the plot is envisioned as the site of new construction, a chance for some profit. If the evaluator is a public official, the land is a lost opportunity, the potential for tax revenue or one more soccer field unexpressed. An evaluation by a landscape architect may recommend a mélange of social programming or a striking design element. If the evaluator is a restoration ecologist, the eyes widen, the pulse quickens, and green visions of a renewed living landscape dance joyfully in the mind.

Can they all be wrong? We take the stance that, ecologically, there's no such thing is an empty lot. The perception of what's not there on the ground can be obvious, but the emptiness of the land is a charade. There are always ecological processes at play on the land and the landscape presence of ecologically useful species upon which to structure a future. Whatever the perceived potential of the site by the evaluator, the land is not empty but full of potential that rests on an invisible foundation. What elements have built that foundation?

There is a land use history. This may be an intangible element of the site and without a careful site analysis we may be unaware of actions which have molded the soil profile and its problems or advantages. This is the Anthropocene and so many landscapes have been populated and modified. A plot of land which is visually empty contains ecological intrusions on its restoration potential which cannot be ignored. Soils can be compacted, polluted, over-fertilized, or filled with varying elements that differ over a very small scale. The site may be empty of easily recognized biota but full of physical problems that the site manager must remediate. One large park in Brooklyn, New York has a parcel which was not developing the healthy upland forest that the managers wanted. Finally, an old map showed that this is where there was an elephant enclosure decades ago when a small zoo was on site. Well, there's compaction for you.

Ecological Restoration Vol. 37, No. 4, 2019

ISSN 1522-4740 E-ISSN 1543-4079

(C2019 by the Board of Regents of the University of Wisconsin System.
There is a soil biota of microbes, a seed pool, and invertebrates. These may not be a historic mix of biodiversity from untouched land, but the mix reflects the quality of the mineral soil and the actions of local migration and extinction of soil-dwelling life. We know that some seed can remain dormant for decades and that many microbes can stay quiescent for years until favorable conditions arise. These living species are invisible to our human eyes, but they can add or subtract to the success of a restoration program. Even if the seed pool is a suite of non-native and ruderal species of plants, when these emerge, they can attract animals to these as foraging or nesting opportunities. Even cracks in urban parking lots, not the locale for a romantic getaway, have been shown to harbor and support over 100 plant species. When these emerge, we get a crack garden that is the first modest stage of a more interesting and diverse ecological community. The animals that have been attracted can themselves bring in seed and pollen of more preferred habitat builders. The weedy species can also attract certain insects who, after colonizing, build the food web that includes more useful biodiversity.

There are adjacencies. Every plot of land is surrounded by landscapes that intrude on its ecological health. Water and nutrient flows, immigration of plants, animals, and other microbes, disturbances, all these are elements that help mold the future of our empty plot. The poet wrote that no man is an island. Similarly, no landscape is isolated; each answers to the pressures of surrounding parcels. Sometimes the adjacencies are benign and contain ecologically rich landscapes. Another parcel may be surrounded by asphalt and high-rise barriers. These factors are part of the equation that yields the future of the site. Those designers and restorationists that focus only on the plot of land which is owned by one client or which is contractually the focus of their work buy into the lie that there is "nothing" around the project location.

The entire field of metapopulation biology has instructed us on how even distant parcels can contribute living elements to a landscape which may be superficially depauperate. An "empty" plot may just be temporarily missing a species which has been a regular colonizer. The rich literature of corridor biology also shows how species across many taxa can move quickly or episodically into a landscape that is currently biotically incomplete proper. If there are adjacencies, the parcel cannot remain "empty." The landscape perspective always exists and biotic communication 
across the focal area will occur. We do not know the tempo or depth of influence across this landscape mosaic, but its mere existence belies the idea that the project site is empty.

These factors are all present and force us to redefine what an empty lot really is. A site may be empty of preferred habitat structure and process but still be full of ecological memories and hurdles to a successful implementation of our restoration vision. Let us say that all sites are full of potential. They also are full of influences from the past and from current surroundings. Whoever controls the site could put on blinders the past, the neighborhood, and the living elements below the surface which can surge into the future as controllers of the lot's emerging biotic personality. The only thing that is truly empty is a restoration plan that ignores the past and the present to build a fantasy future.

\section{Recommended Readings}

Bennett, A.F., 2003. Linkages in The Landscape: The Role of Corridors and Connectivity in Wildlife Conservation. Gland, Switzerland: IUCN.

Frazee, L.J., M.F. Aronson, J. Kattge, and L. Struwe. 2019. Hardscape floristics: Functional and phylogenetic diversity of parking lot plants. Applied Vegetation Science doi.org/10.1111/avsc. 12450.

Hanski, I. 1999. Metapopulation Ecology. Oxford, UK: Oxford University Press.

Harris, J. 2009. Soil microbial communities and restoration ecology: facilitators or followers? Science 325:573-574.

Wall, D.H., K. Ritz, J. Six, D.R. Strong and W.H. van der Putten. 2012. Soil Ecology and Ecosystem Services. Oxford, UK: Oxford University Press.

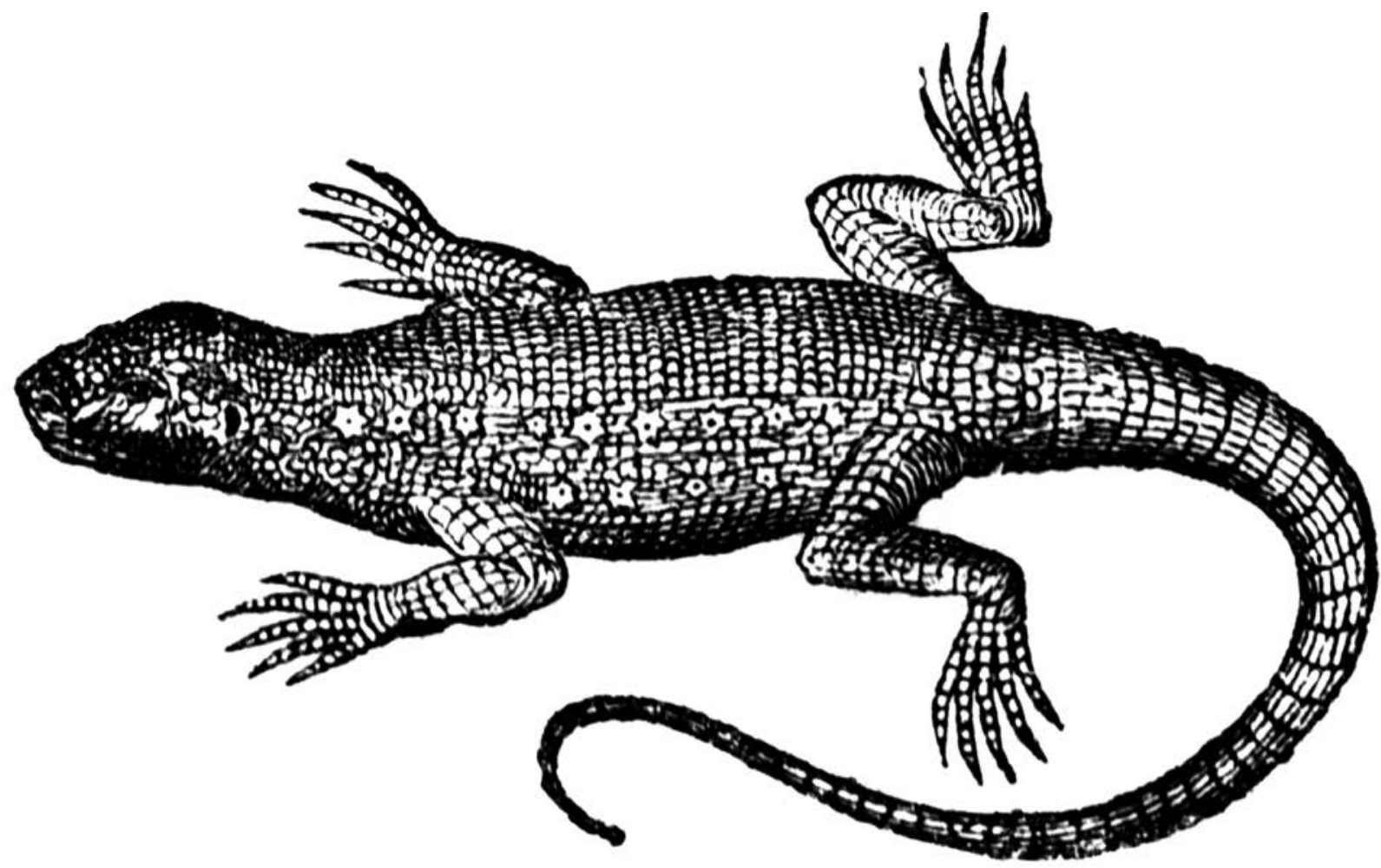

Lizard. Schäk, J. (1874) Drittes Lesebuch. New York, NY: Fr. Pustet. The Florida Center for Instructional Technology, fcit.usf.edu. 